\title{
Induction and inheritance of determinate growth habit in chickpea (Cicer arietinum $\mathbf{L}$.)
}

\author{
H.A. van Rheenen, R.P.S. Pundir \& J.H. Miranda \\ International Crops Research Institute for the Semi-Arid Tropics (ICRISAT), * Patancheru 502 324, A.P., India
}

Received 22 September 1993; accepted 17 June 1994

Key words: chickpea, Cicer arietinum, determinate growth habit, mutation

\section{Summary}

The character of determinate plant growth has not been reported for chickpea and has not been observed in the world germplasm collection at ICRISAT, Patancheru, India. A determinate growth habit would be desirable where growing conditions often lead to excessive vegetative growth. We attempted to generate this trait by mutation breeding. Seeds of the cultivar ICCV 6 were exposed to varying irradiation treatments, $M_{1}$ and $M_{2}$ populations were raised, and in the latter one plant was detected that showed the determinate growth habit and female sterility. The character of determinate growth segregated in a postulated digenic epistatic 3:13 fashion in the $F_{2}$ and confirmed its digenic mode of inheritance in the $\mathrm{F}_{3}$ and $\mathrm{F}_{4}$. The symbol $\underline{\mathrm{cd}}$ is proposed for the allele conditioning for determinancy and $\underline{D t}$ for the allele expressing the determinate trait. Continued mutation breeding with this and other material may result in identifying fully fertile, determinate plant types.

Abbreviations: DT - determinate, IDT - indeterminate

\section{Introduction}

Several legumes, such as common bean (Phaseolus vulgaris L.), soybean (Glycine max (L.) Merr.), and pigeonpea (Cajanus cajan (L.) Huth) can show either DT or IDT growth habit. One single recessive gene causes the common bean plant to grow determinately (Tulmann Neto \& Alberini, 1989), and in soybean and pigeonpea the character is controlled oligogenically (Palmer \& Kilen, 1987; Gupta \& Kapoor, 1991). In chickpea (Cicer arietinum L.), the occurrence of DT growth habit, whereby stem and branch apices terminate in flowers, has not been reported. This seems surprising, as the world germplasm collection contains a large number of well studied and documented accessions. The character would not likely be overlooked since it is important for improving plant type and yield stability (Pundir et al., 1988). It seems, therefore, that it is absent or very rare.

ICRISAT holds a collection of 16346 chickpea germplasm accessions and 98 accessions belonging

\footnotetext{
* ICRISAT Journal Article No. 1396.
}

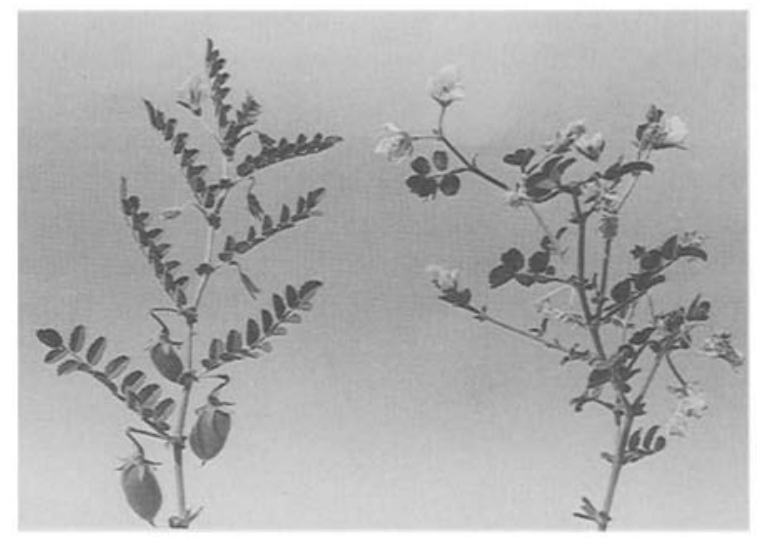

Fig. 1. Left: ICCV 6 (normal) with vegetative stem apex, right: mutant with reproductive stem apex and reduced number of leaflets.

to 14 wild Cicer species. The Cicer arietinum accessions originated in 42 countries representing diverse geographical variation and vast diversity of morphoagronomic traits, including six classes of flower color, 


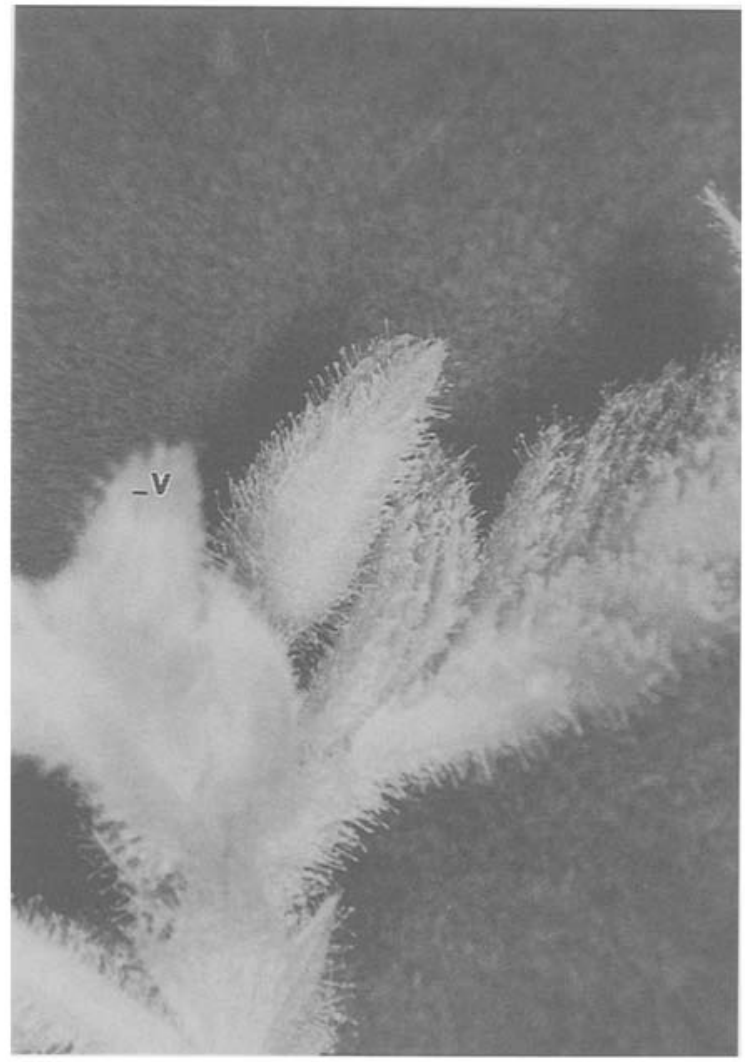

Fig. 2 a. Parent chickpea ICCV 6 (normal) with vegetative stem apex $(v)$;

18 classes of seed color, leaf canopy from prostrate to fully erect, leaf size from 1.99 to $10.26 \mathrm{~cm}^{2}$ and of various botanical forms, and 100 -seed mass varying from 3.8 to $59.1 \mathrm{~g}$ (Pundir et al., 1988). The objectives of this study were to use mutagenesis to induce DT growth into a plant of good agronomic background and to study the inheritance of the DT trait.

\section{Materials and methods}

The widely adapted, wilt resistant kabuli cultivar ICCV 6 was selected for mutagenesis. It has cream colored seeds with a 100-seed weight of approximately $22 \mathrm{~g}$. Batches of dry seed of $1.5 \mathrm{~kg}$ each were irradiated with gamma rays at doses of 15,30 , and $45 \mathrm{k}$ Rad in 1986. The $M_{1}$ populations were growth in a field of the vertisol type at ICRISAT center during 1986/87 and the $\mathrm{M}_{2}$ populations, having a total of $1.8 \times 10^{5}$ plants, during $1987 / 88$. The mean germination percentage of the $F_{1}$ seed was 37 .

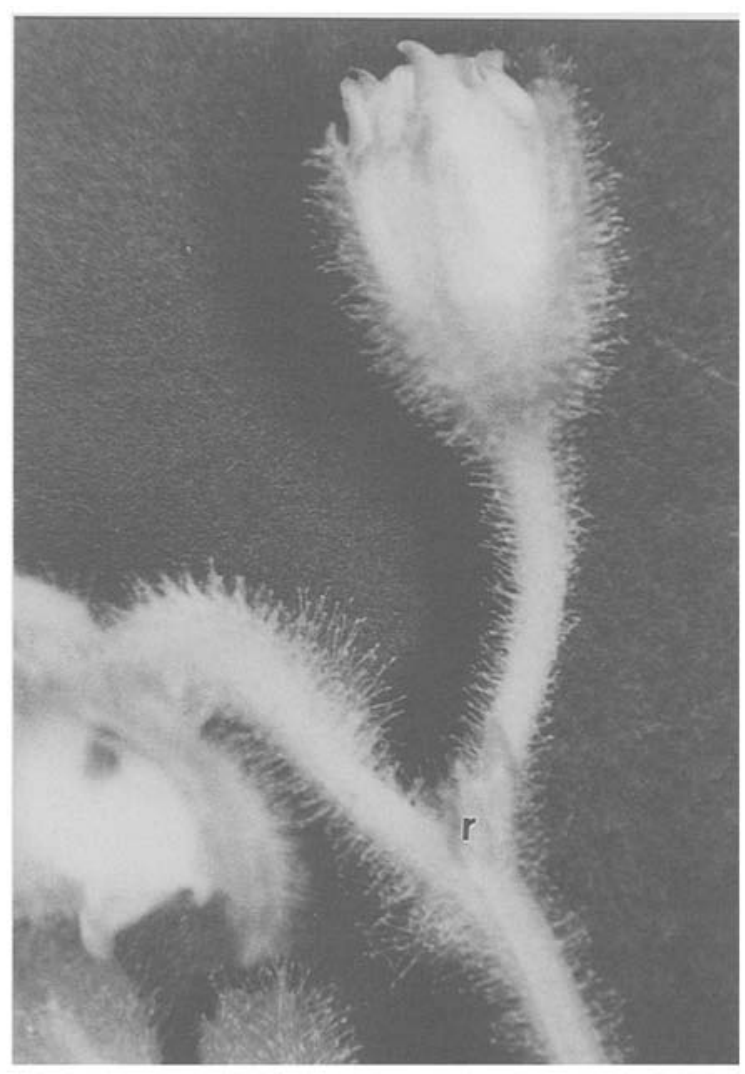

Fig. 2 b. Mutant with reproductive stem apex (r).

To preserve the DT character of a non-podding plant we attempted to cross it reciprocally with neighboring plants of the same $\mathbf{M}_{2}$ population and obtained $11 F_{1}$ seeds from normal chickpea (IDT) plants only. The $F_{1}$ plants were grown in 1988 and $460 \mathrm{~F}_{2}$ plants in $1989 / 90$. Three hundred and seventy IDT $F_{2}$ plants were harvested separately and their $\mathrm{F}_{3}$ progenies were grown during 1991/92. We recorded the number of segregating and non-segregating progenies that had 15 plants or more, and for all progenies we counted the number of DT and IDT plants. The IDT plants of the segregating $F_{3}$ progenies were bulk harvested and for the $F_{4}$ population we counted the DT and IDT plants.

Pollen fertility was determined by staining pollen grains from DT and IDT plants with $2 \%$ acetocarmine solution. Pollen grains were considered fertile if they were darkly stained and had regular shapes. For scanning electron micrsocopy anthers and pollen grains were stuck on double sided sticky tape fixed to aluminum stubs, desiccated overnight in the presence of 


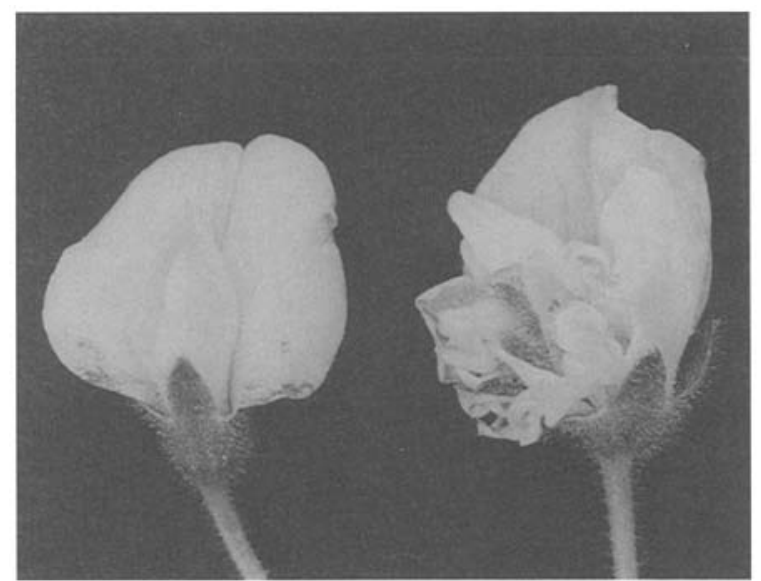

Fig. 3 a. Left: ICCV 6 (normal flower), right: mutant (malformed flower);

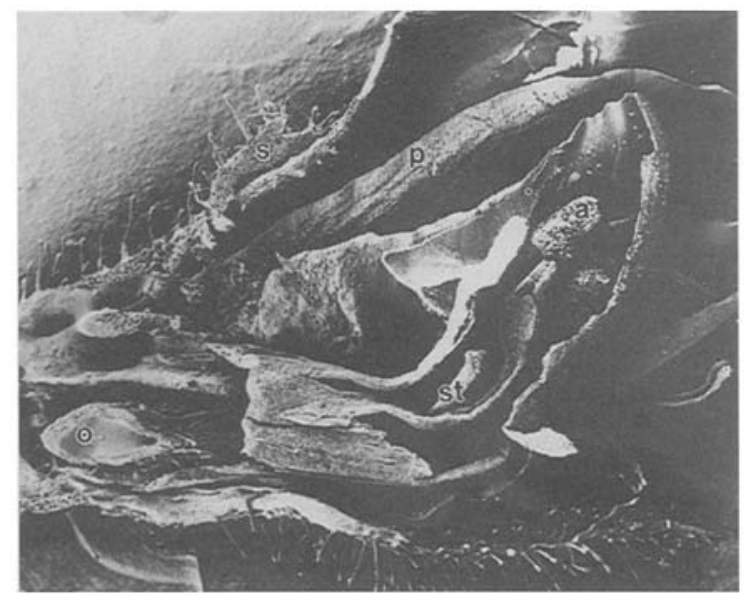

Fig. $3 \mathrm{~b}$. Scanning electron micrograph of longitudinal section of flower of ICCV 6 (normal) with sepals (s), petals (p), anther (a), style (st) and ovary (o).

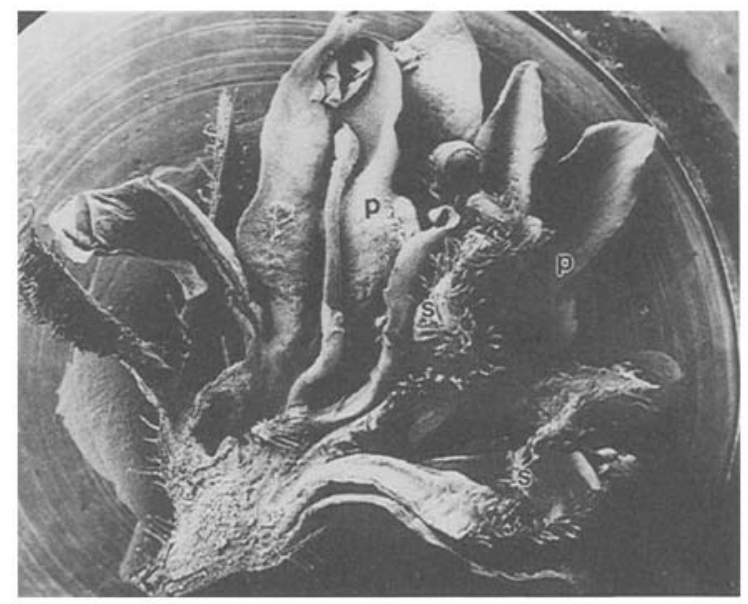

Fig. 3 c. As $3 \mathrm{~b}$ for mutant with repeated sepal (s) and petal-like (p) structures. silica gel, spatter coated with gold $(200 \mathrm{~nm})$, and observed in a JOEL JSM 35-CF scanning electron microscope at $15 \mathrm{KV}$. Similarly, longitudinal sections of flowers were inspected with the scanning electron microscope.

\section{Results and discussion}

We found a plant with DT growth habit in the $\mathrm{M}_{2}$ population of the $15 \mathrm{k} \mathrm{Rad}$ treatment. The plant flowered profusely, but failed to form pods, both, naturally and with hand-pollination.

\section{Plant and pollen morphology}

The DT plant was morphologically determinate, had a bushy growth habit and a reduced number of leaflets per leaf compared with ICCV 6 (Figs 1 and 2). The flowers were malformed with repeats of sepal- and petallike structures and lacked a gynaecium (Fig. 3). The anthers contained pollen that appeared almost normal when stained with acetocarmine and examined under the optical microscope. Scanning electron microscopy revealed the pollen from DT plants to be more rounded, smaller, and less reticulated than pollen from IDT plants (Fig. 4).

\section{Inheritance of the determinate character}

The $F_{1}$ plants appeared to be normal and IDT, suggesting that DT growth is recessive. The $F_{2}$ produced $81 \mathrm{DT}$ and 379 IDT plants giving a ratio of DT:IDT (1:4.68) that could not support the hypothesis of monogenic inheritance of the DT growth trait, but the hypothesis of digenic epistatic inheritance resulting in a 3:13 ratio could not be rejected. The $\mathrm{F}_{3}$ data sets, giving the number of progenies showing segregation, the number of DT and IDT plants in those progenies and the number of total DT and IDT plants supported the hypothesis and so did the $\mathrm{F}_{4}$ data (Table 1). In accordance with proposed nomenclature (Muehlbauer \& Singh, 1987), we suggest that the symbol $\underline{c d}$ be used for the recessive allele that conditions a plant for expressing the determinate plant character, and $\underline{D t}$ for the allele that controls the trait.

Chickpea is usually grown on residual moisture. Under warm climatic conditions at lower latitudes, for instance in Ethiopia (4-18 $\mathrm{N}$ ), the plants mature early due to drought stress and usually do not grow tall. But under cooler climatic conditions at higher latitudes, 


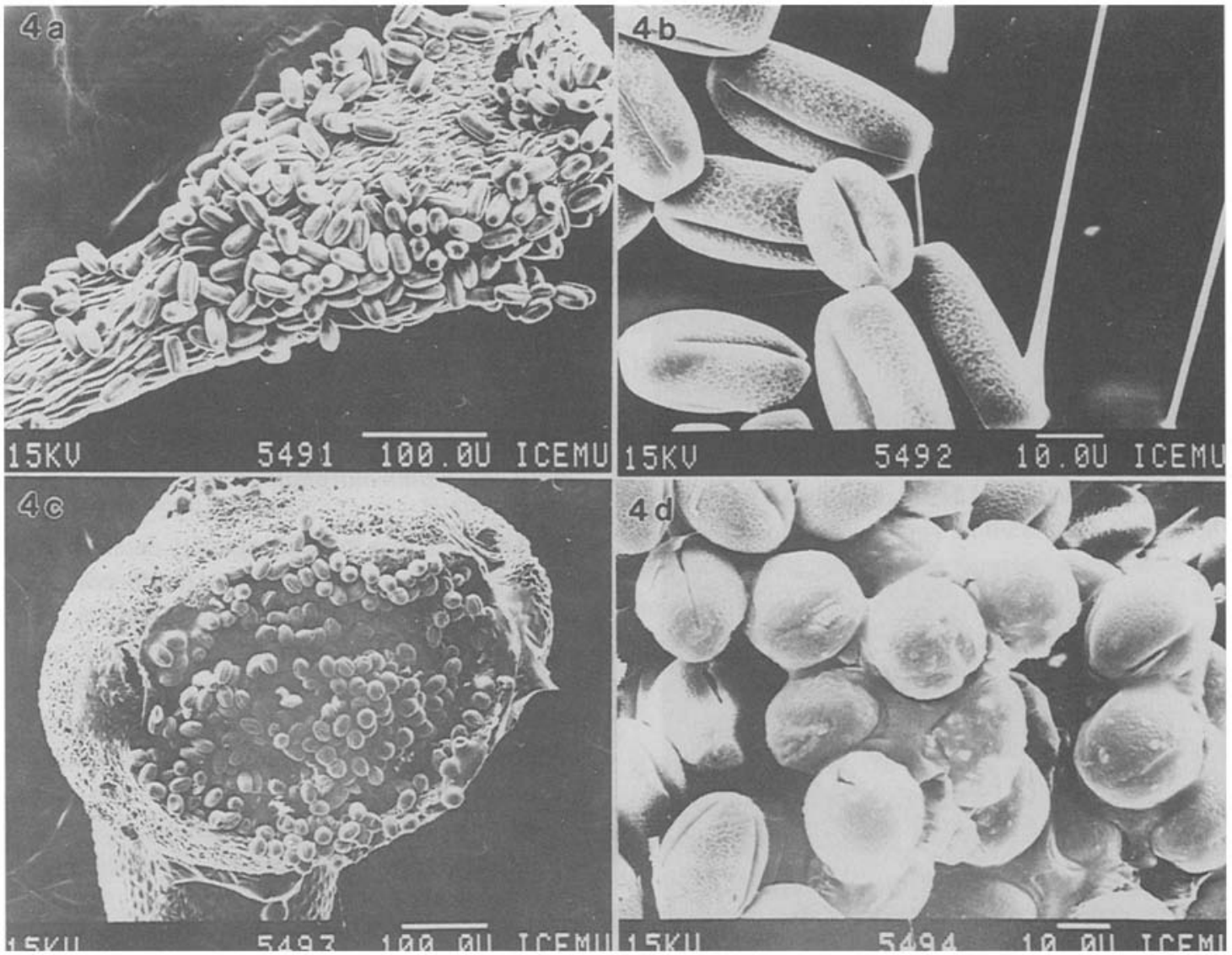

Fig. 4. Anther and pollen of normal and determinate chickpea plants. (a): Normal anther; (b): Normal pollen; (c) Anther of determinate plant; (d): Pollen of determinate plant.

Table 1. Segregation (seg) of determinate (DT) plant growth habit in crosses between indeterminate (IDT) ICCV 6 and determinate (DT) mutant ICCV $6 \mathrm{M}$

\begin{tabular}{|c|c|c|c|c|c|c|c|c|}
\hline \multirow[t]{2}{*}{ Genotype } & \multicolumn{3}{|c|}{ Observed numbers ${ }^{1}$} & \multicolumn{3}{|c|}{ Expected ratio } & \multirow[t]{2}{*}{$x^{2}$} & \multirow[t]{2}{*}{$P(\%)$} \\
\hline & DT & IDT & seg & DT & IDT & seg & & \\
\hline ICCV 6 & - & + & - & - & + & - & & \\
\hline ICCV $6 \mathrm{M}$ & + & - & - & + & - & - & & \\
\hline$F_{1}$ plants & 0 & 11 & - & 0 & 11 & - & & \\
\hline$F_{2}$ plants & 81 & 379 & - & 3 & 13 & - & 0.394 & $0.50-0.60$ \\
\hline $\mathrm{F}_{3}$ families & 0 & 65 & 53 & 0 & 7 & 6 & 0.073 & $0.70-0.80$ \\
\hline$F_{3}$ plants $(\mathrm{Segr})^{2}$ & 230 & 792 & - & 5 & 19 & - & 1.732 & $0.15-0.20$ \\
\hline$F_{3}$ plants (total) & 367 & 3436 & - & 5 & 47 & 0 & 0.006 & $0.90-0.95$ \\
\hline $\mathrm{F}_{4}$ plants $(\mathrm{Segr})^{3}$ & 127 & 873 & - & 9 & 67 & 0 & 0.706 & $0.30-0.50$ \\
\hline
\end{tabular}

1 - = none; $+=$ all

${ }^{2}$ Segregating progenies with 15 or more plants.

${ }^{3}$ From segregating $F_{3}$ progenies. 
e.g., in the states of Haryana and Punjab, India (27$32^{\circ} \mathrm{N}$ ), and even in low lying areas of the Thal desert in Pakistan $\left(31-32^{\circ} \mathrm{N}\right)$, chickpea may show abundant vegetative growth and be prone to lodging. Because of lodging, total crop losses can occur. The authors have seen chickpea lodged from wind and transformed into a thick carpet that failed to produce marketable seed. The DT growth habit is likely to curb excessive vegetative growth and reduce the risk of lodging. A number of crops (Filippetti, 1986; Steele et al., 1984; Gupta \& Kapoor, 1991; Fehr, 1987; Julier et al., 1993) have gained significant advantage with DT growth habit.

Unfortunately, the DT plants in this study were female sterile. As a consequence, the $\underline{c d} \underline{c d} \underline{D t}$ : allelic combination has to be maintained in the double $(\underline{C d}$ $\underline{c d} \underline{D t} \underline{d t})$ or single ( $\underline{C d} \underline{c d} \underline{D t} \underline{D t})$ gene heterozygous state. Renewed attempts of mutation breeding may possibly lead to the development of fertile DT plants. For that purpose seeds of $\underline{C d} \underline{c d}$ and $\underline{c d} \underline{c d}$ plants may be included in the efforts. It would be interesting to study the molecular basis for the observed phenomena, as it may help to understand and influence the mechanism of growth habit determination.

\section{Acknowledgements}

We are grateful to the ICRISAT Chickpea Breeding field staff for conducting the trials, to S. Ramakrishna for doing the countings and to M.S. Raghavan and V. Sashikala for typing the manuscript. The photographic contributions by D.V.R. Reddy, A.B. Chitnis, and the scanning electron microscopy by A.K. Murthi and S.K. Manohar are gratefully acknowledged.

\section{References}

Fehr, W.R., 1987. Breeding methods for cultivar development. In: J.R. Wilcox (Ed.). Soybeans, improvement, production and uses, 2nd ed., pp. 249-293. (No. 16 in the series: Agronomy.) American Society of Agronomy, Inc.; Crop Science Society of America, Inc.; Soil Science Society of America, Inc.; Madison, Wisconsin, USA.

Filippetti, A., 1986. Inheritance of determinate growth habit induced in Vicia faba major by ethyl methane sulphonate (EMS). Fabis News 15: 12-14.

Gupta, S.C. \& R.K. Kapoor, 1991. Inheritance of growth habit in pigeonpea. Crop Sci. 31: 1456-1459.

Julier, B., C. Huyghe, J. Papineau, G.F.J. Milford, J.M. Day, C. Billot \& P. Mangin, 1993. Seed yield and yield stability of determinate and indeterminate autumn-sown white lupins (Lupinus albus) grown at different locations in France and the UK. J. of Agr. Sci., Cambridge 121: 177-186.

Muehlbauer, F.J. \& K.B. Singh, 1987. Genetics of chickpea. In: M.C. Saxena \& K.B. Singh (Eds). The chickpea, pp. 99-125. C.A.B. International, Wallingford, U.K.

Palmer, R.G. \& T.C. Kilen, 1987. Qualitative genetics and cytogenetics. In: J.R. Wilcox (Ed.). Soybeans: improvement, production and uses, 2nd ed., pp. 135-209. (No. 16 in the series: Agronomy.) American Society of Agronomy, Inc.; Crop Science Society of America, Inc.; Soil Science Society of America, Inc.; Madison, Wisconsin, USA.

Pundir, R.P.S., K.N. Reddy \& M.H. Mengesha, 1988. ICRISAT chickpea germplasm catalog: evaluation and analysis. ICRISAT, Patancheru, A.P. 502 324, India.

Steele, W.M., D.J. Allen \& R.J. Summerfield, 1985. Cowpea (Vigna unguiculata (L.) Walp.). In: R.J. Summerfield \& E.H. Roberts (Eds). Grain Legume Crops, pp. 520-583. Collins, London, UK.

Tulmann Neto, A. \& J. Alberini, 1989. Release to farmers of 'Carioca Arbustivo Precoce 1070' (CAP-1070), a bushy bean mutant induced by gamma rays in Brazil. Mutat. Breed. Newsl. 34: 1213. 